\title{
DEVELOPMENT OF SPECIFIC MATHEMATICAL COMPETENCES FOR PLANE FIGURES IN THE EDUCATION IN MATHEMATICS FOR GRADES 1 - 4 Maria Temnikova $^{1}$
}

\begin{abstract}
:
INTRODUCTION: The development of specific mathematical competences from the competency cluster "Plane figures" is one of the important factors for achieving effective education in mathematics in primary school.

PURPOSE OF STUDY: The purpose of this article is the presentation of the competences concept and especially the concept of the objective specific mathematical competences as well as the options for their development in and through education in mathematics in Grades 1-4.

METHODS: During the experimental work the researchers performed qualitative and quantitative study of the topics presented above. The following methods were applied: a didactical experiment, observation, test, content analysis, and a mathematicalstatistical method for data processing.

RESULTS: As a result of the experimental work it was determined that the percentage of fourth graders who failed to solve a geometry text task decreased from $49.61 \%$ to $9.32 \%$. The percentage of those students who failed to draw a circle with a given radius and an angle according to a given grade decreased from $38.95 \%$ to $8.17 \%$. Additionally, the percentage of the students who correctly solved a geometry text tasks increased from $15.2 \%$ to $23.1 \%$. The difference in the results is proven to be of statistical significance.

CONCLUSIONS: Owing to the applied methodology system of work where productive strategies, methods and approaches were used, the specific mathematical competences from the competency cluster "Plane figures" were developed in their completeness in primary school students.
\end{abstract}

UDC Classification: 37; DOI: http://dx.doi.org/10.12955/cbup.v6.1252

Keywords: plane figures, productive strategies, specific mathematical competences

\section{Introduction}

In the Republic of Bulgaria, changes related to the education in mathematics for Primary School students started in 2015 . They were induced by dynamic changes in the society and were directed towards the improvement of the quality of education in line with the new conditions. This required reconsidering the pedagogy reality in its most important aspects - expected results, educational content and educational process as a whole. At this stage development of specific mathematical competences and mathematical competencies in students is the leading direction of the educational process in mathematics for Grades $1-4$.

\section{Aim, object, and subject of the study}

The aim of the research is to systematize and present basic theoretical concepts regarding specific competences. Then on the basis of this to develop a methodology system of work, a series of mathematical tasks as well as to study the level of development of these mathematical competences from the competency cluster "Plane figures" in and through education in mathematics for Grades 1-4.

The subject of the research is the educational process in mathematics for Grades 1-4.

The object of the research is the effect of the combined application of productive and reproductive strategies, their respective approaches and methods of work for the development of specific competences from the cluster "Plane figures" in the education of mathematics for Grades 1-4 as part of the newly developed methodology system of work.

To achieve the goal of the research the following tasks were completed:

1. A study and theoretical analysis of: research work of foreign and Bulgarian authors related to the competency approach and the competences. In addition to this concepts regarding strategies (problem-productive and reproductive), pedagogy technologies and methods were researched.

2. A study of the legal documentation, identification and systematizing of the specific mathematical competences and presentation of the specific interrelations typical for them.

3. A study of the main characteristics of the problem-productive strategies and their application in the process of development of a technology and methodology system of work. An application of the

\footnotetext{
${ }^{1}$ Trakia University - Stara Zagora, Faculty of Education, e-mail: mpt66@abv.bg
} 
problem-productive strategies in the education of mathematics aiming at the development of specific mathematical competences from the competency cluster "Plane figures".

4. A study the efficiency of the applied problem-productive strategies in the methodology system of work in the educational process in mathematics for Grades 1-4. A comparative analysis and assessment of the results from the empiric study, a summary and finally the formulation of conclusions.

For the purposes of the empiric study the following criteria were introduced: knowledge and skills to recognize a straight line and a curve; beam, line segment, angle, triangle, rectangle, square, circle and their elements; to draw a line segment as per a pre-defined length, an angle as per a pre-defined degree; to draw a triangle and a rectangle on a square mesh paper; the knowledge and skills to determine the type of an angle and triangle; to solve a geometry task.

The main goal of education in mathematics by the end of the primary school is for the students to acquire a certain level of competences and competencies from their years of study of mathematics in primary school

The terminology competency and competence lay in the foundation of the Competency approach. Over the recent decades this approach was widely applied in EU countries, the US, Russia, etc.

The analysis of international pedagogy literature identified numerous research works studying the issues related to "competences". This includes the works of Boritko (2007), Delore (1996), Karamanov (2005), Hutorskiy (2005), Hutmacher (1996), While (1959) and other. A number of Bulgarian researchers also worked on the topic of competences. These are Radoynovska (2005), Delcheva (2012), Velikova (2003) and other. All definitions have in common the understanding that competences represent a person's ability to manage and resolve different tasks.

V. Hutorskiy recognized the synonymous use of the terminology competence and competency. His understanding is that competence is "an estranged pre-set social requirement (norm) to the education of the student, necessary for his efficient productive activity in a certain area". (Hutorskiy, 2002). According to him some competences are more important and more general than others. He believes that following the separation of education to "general subjective" (for all subjects) and "subjective" (for every separate educational subject) the following hierarchy with "three levels" of competences can be built: "key competences - they are referred to the general (meta-subjective) content of education. These competences are established in educational areas and educational subjects level for each Grade; general subjective competences - they are referred to a certain circle of educational subjects and areas of education; subjective competences - this is a special case to the above two levels of competences. They are developed and are described within the framework of the educational subjects". (Hutorskiy, 2002)

Studying the terminology for competences in depth, Delcheva segregated two types of competences: key competences and specific, differentiated competences. The latter she determined as related to knowledge, skills, and assessment ability of the person towards a certain area. They are pre-conditioned for achieving quality and precision of the results in a given sphere. (Delcheva, 2012)

This hierarchy and competence levels were adopted for the purposes of the research work. Special attention was paid to specific mathematical competences. During the course of education in mathematics for Grades 1-4 in the competences cluster "Plane figures" the students acquire knowledge, skills and developed competences regarding the following: line segment, straight line, curve, beam, angle, types of angle, triangle, square, rectangle, circle, circumference and their elements. As the aim of the research is to develop specific mathematical competences, this required their systematizing based on the contemporary legal documentation. The research did broad analysis of the following: requirements of the educational mathematical content for Primary School as well as of the educational programs in mathematics for Grades 1-4. Based on this the following specific interrelations were identified. Please note that this document presents the abovementioned interrelations only partially:

- Interrelations between specific mathematical competences belonging to different competency clusters:

The Figure 1 expressed the interrelations between competency clusters "Numbers" (K1), Plane figures" (K2), "Measuring" (K3) and "Modelling" (K4). The interrelations in question are based on a spiral evolution principle and the principle of integrity (knowledge and skills from the area of geometry are 
introduced together with knowledge and skills from the areas of arithmetic and algebra where the arithmetic ones are the ones leading.)

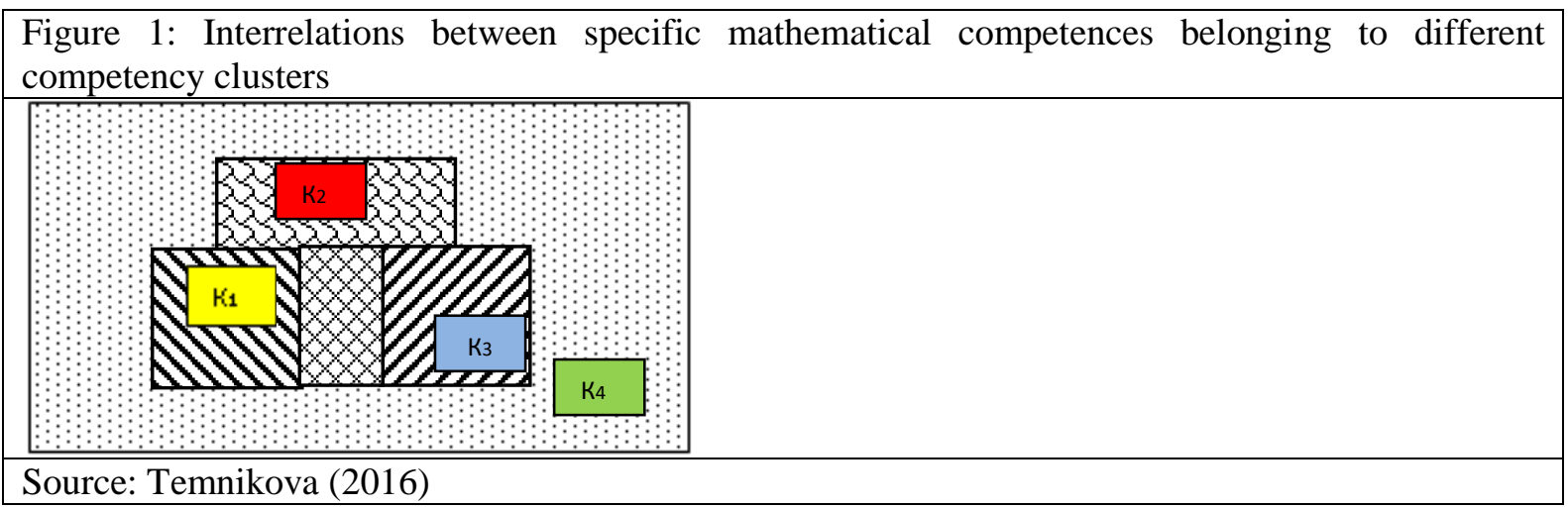

- Interrelations between specific mathematical competences and main terminology from the competency cluster "Plane figures" of the educational content in mathematics for Grades 1-4. These interrelations are partially represented in the below figures:

Figure 2: Interrelations between specific mathematical competences and the main terminology from the competency cluster "Plane figures" of the educational content in mathematics for Grades 1-4

\begin{tabular}{|c|c|c|}
\hline $\begin{array}{l}\text { Competency } \\
\text { cluster }\end{array}$ & $\begin{array}{c}\text { Specific mathematical } \\
\text { competency }\end{array}$ & $\begin{array}{c}\text { New } \\
\text { terminology }\end{array}$ \\
\hline Plane figures & $\begin{array}{l}\text { Recognize geometry } \\
\text { figure "angle" and its } \\
\text { elements }\end{array}$ & $\begin{array}{c}\longrightarrow \text { angle } \\
\longrightarrow \text { apex } \\
- \text { arm }\end{array}$ \\
\hline
\end{tabular}

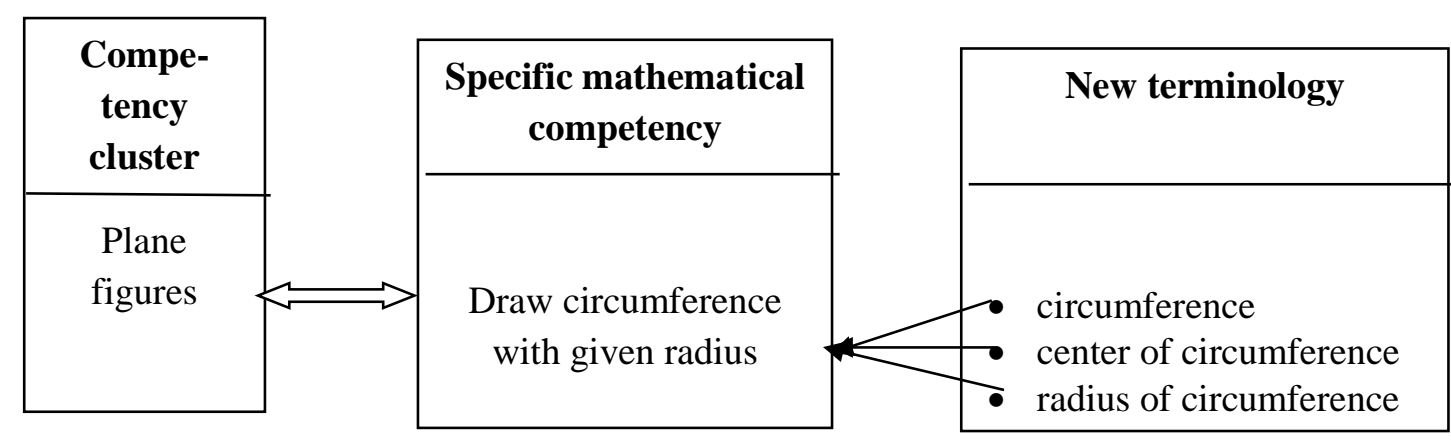

Source: Temnikova (2016)

The new methodology system of work combines the problem-productive strategy, productive approaches and methods as well as reproductive ones. This system of work shall be systematically applied during mathematics classes both in compulsory and in optional education in mathematics.

According to many researchers (including Babanskiy, 1989 and Johnson, 1985) the problem-productive strategy makes the educational process more active. The work with this type of strategy is related to the creation and resolving of problem situations in the course of mathematical tasks solving. Studying the problem resolving process from a general point of view, Mahmoutov determined that the aim of problem-oriented education is not only acquiring the results of the scientific study but also the way and the process of receiving these results". (Mahmoutov, 1997, pp. 20-40)

The main pillars in the process of the creation of a series of mathematical tasks needed for the purposes of the educational process are: they are a "major tool" for the development of specific mathematical competences and include mathematical tasks which form separate elements of those specific 
mathematical competences from a competency cluster 'Plane figures". These tasks are complimentary to each other and create "complex repeating situations". (Petrov, Temnikova, 2016)

\section{Results}

During the period between 2004 and 2012, research was carried out with the purpose to study the development of specific mathematical competences from the competency cluster "Plane figures" in the education of mathematics for Grades 1. - 4. Two classes of students with statistically equal levels of educational achievements were subjected to the study. One of the classes was the experimental one where the new methodology system of work was applied and the second (referent) one where the traditional methodology of work in the education in mathematics was applied. (Temnikova, 2016)

The diagnostic tool was developed after studying and analysing the international projects TIMSS, PIRLS and PISA from one side, and from the other - after analysing the options for tests for external assessment of the educational achievements in mathematics of Grade 4 students as well as the requirements for compliance with the Bulgarian state provisions for education in mathematics for Grades 1. - 4. Two tests were used in the empiric study: one to determine the entry diagnostic and the second to determine the exit diagnostic of the knowledge, skills and competences of the students in the competency cluster "Plane figures". The research studied the objectiveness, the validity and the reliability of the tests as well as the level of difficulty and the segregation strength of the mathematical tasks included in them.

The results of the tests were analysed including the performance of comparative analysis. The results of the comparative analysis of the entry and the exit diagnostic regarding the knowledge and skills to recognize a straight line, curve, beam, line segment, angle, triangle, rectangle, square, circle and their elements; to draw a line segment as per a pre-defined length, an angle as per pre-defined degree; to draw a triangle and a rectangle on square mesh paper; the knowledge and skills to determine the type of an angle and a triangle and to solve a geometry task are presented in the below two diagrams.

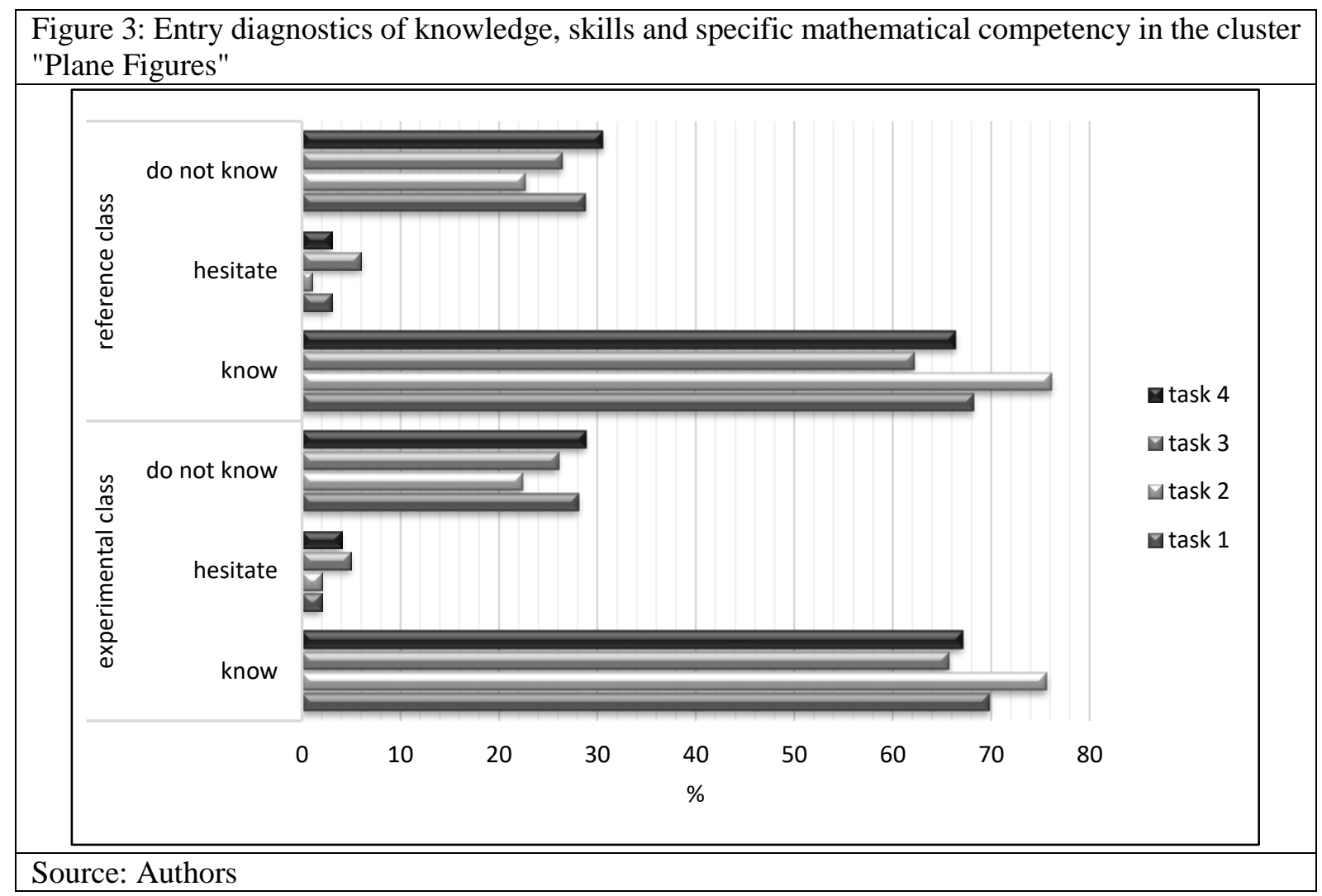

The result from the entry diagnostic showed that there is no statistically significant difference between the relative segments of students from the experimental and from the referent class subjected to the study in respect to their knowledge, skills and competences. However, as a result of the experimental work the exit diagnostic identified significant difference between the results of the experimental and the referent classes. Failure to recognize line segment and curve, beam, angle, triangle, rectangle, square, circumference and their elements is evident for $9.32 \%$ of the experimental class whereas this percentage 
is $19.11 \%$ for the students in the referent class. The percentage of the students who fail to draw a line segment as per a given value, an angle as per a given degree, a triangle rectangle on square mesh paper was reduced down to $7.17 \%$ for the experimental class whereas this percentage in the referent class was $18.95 \%$. The level of knowledge, skills and competences of the students from the experimental class who correctly determined the type of angle and triangle increased from $65.7 \%$ to $94.36 \%$ whereas the same percentage of students from the referent class increased from $62.18 \%$ to $83.81 \%$. The percentage of the students from the experimental class who correctly solved geometry tasks increased from $15.22 \%$ to $23.17 \%$ and the percentage of the students from the referent class increased from $11.46 \%$ to $14.19 \%$. The difference in the results was proved to be statistically significant.

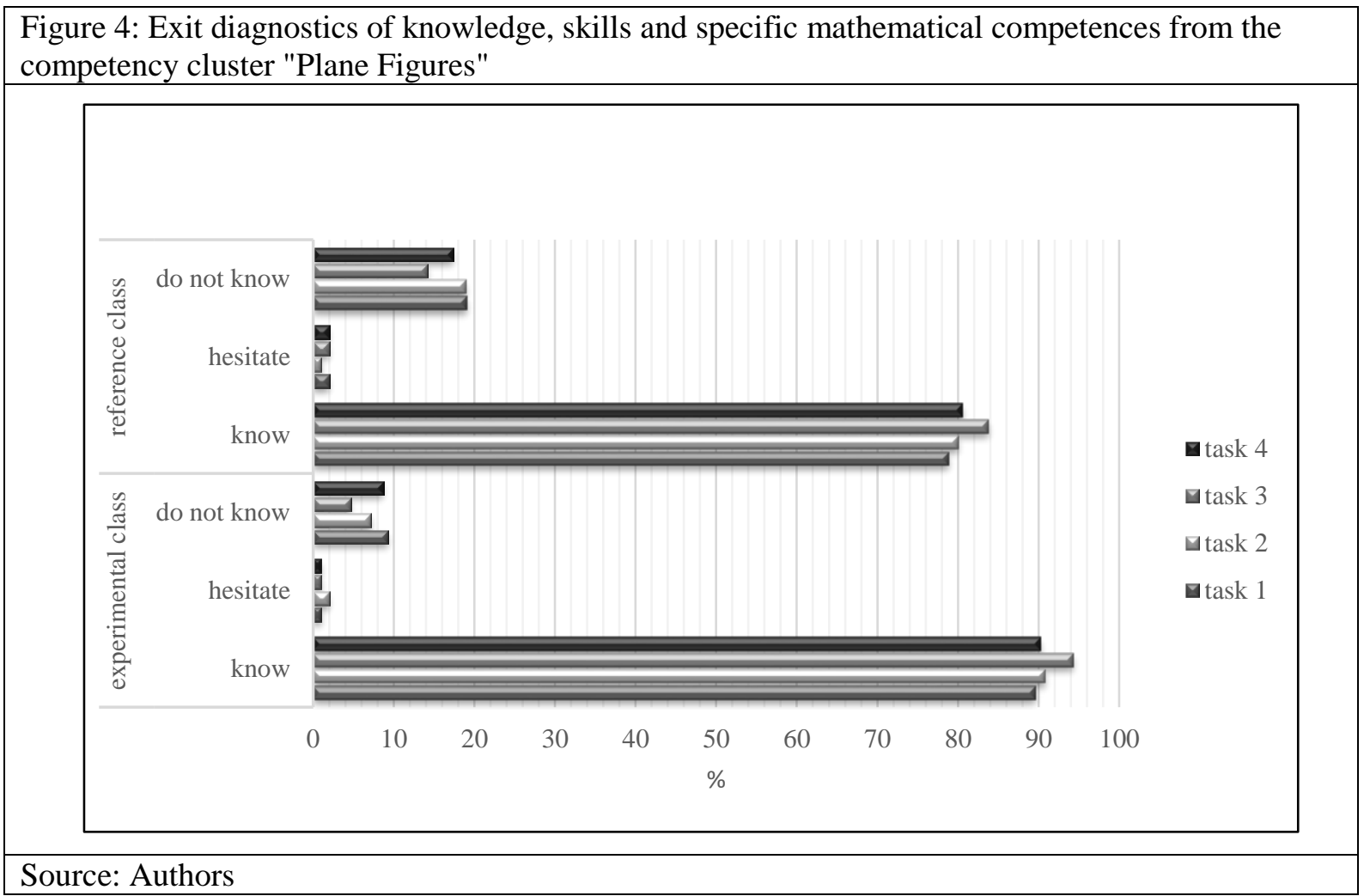

\section{Conclusion}

Based on the results received from the research, the following conclusions can be made: owing to the applied new methodology system of work, the students from the experimental class developed higher a level of knowledge, skills and specific mathematical competences from the competency cluster "Plane figures" in comparison with those developed by the students from the referent class.

As a result of the identification of the specific mathematical competences from the competency cluster "Plane figures" for the educational content for Grades 1. - 4. The following was achieved: a clear idea regarding the starting point of the methodology work of the teacher aiming at development of a concrete competence. One can see the directions which require specific methodology activity for development of competences and competencies in the students. Interrelations and influence of the development of concrete competence on another one is clearly visible.

The application of problem-productive strategies in the education of mathematics for Primary School facilitates the process of development of mathematical competencies, and specific and key competences in primary school students.

\section{References}

Babanskiy, Y. ( 1989). Chosen pedagogy works, Moscow, Pedagogy magazine.

Boritko, N. M. (2007). Professional pedagogy competency of the teacher, Retrieved March, 9, 2007, from http: // www. eidos.ru/ journal/ 2007/ 0930-10.htm.

Delcheva, T. (2012). Key competences of the children entering Grade I, report to Scientific-practical conference "Reality and traditions of the pre-school education", Stara Zagora.

Delore J. (1996). Education: hidden treasure, UNESCO. 
Houtorskiy, A. V. (2002). Key competences and educational standards// Report regarding separation of the educational philosophy and pedagogy theory, RAO, Eidos center, Retrieved April 23, 2002, from http: //www .eidos.ru/news/compet/htm.

Houtorskiy, A. V. (1997). Key and objective competences in school education, Person-oriented aspects in the modernization of education, Report in a seminar, Town of Nizhniy Tagil, 10-12.01.2005.

Hutmacher Walo. Key competencies for Europe // Report of the Symposium Berne, Switzerland 27-30 March, 1996. Council for Cultural Cooperation (CDCC) a // Secondary Education for Europe, Strasburg.

Johnson, J. (1985). Introduction to the Foundations of American Education. Boston, Allyn and Bacon.

Mahmoutov, M. (1977). Organization of the problem education at school, Moscow, Prosveshtenie magazine.

Petrov, P. D. (2011). Methodology for education in mathematics in primary school/ reflection of the concept for the mathematical tasks solving skill, Stara Zagora.

Radoynovska, B. (2005). The Competences - priority of the education. Pedagogika magazine, № 5.

Temnikova, M. (2016). Development of transversal competencies in the education in mathematics for Grade I1 - 4. Scientific study, Stara Zagora.

Velikova, V. (2003). Educational competency as a result of the educational activity, Pedagogika magazine, № 6.

While, R. W. (1959). Motivation reconsidered: The concept of competence. Psychological review, № 66. 